\title{
Thyroid surgery in children and young adults: potential overtreatment and complications
}

\author{
Julia I. Staubitz ${ }^{1}$. Julia Bode ${ }^{2}$ - Alicia Poplawski ${ }^{3} \cdot$ Felix Watzka $^{1} \cdot$ Joachim Pohlenz $^{4} \cdot$ Hauke Lang $^{2}$. \\ Thomas J. Musholt ${ }^{1}$ (I)
}

Received: 28 December 2019 / Accepted: 15 May 2020 / Published online: 27 May 2020

(C) The Author(s) 2020

\begin{abstract}
Purpose Thyroid nodules in the pediatric population are more frequently associated with malignant thyroid disease than in adult cohorts. Yet, there is a potential risk of surgical overtreatment. With this single center study, an analysis of potential overtreatment for suspected malignant thyroid disease in children and young adults was aimed for.

Methods In a period from 2005 to 2018, 155 thyroid operations in children and young adults performed at the University Medical Center Mainz, Germany, were analyzed (patient age 3-20 years, 117 female). Cases were categorized for preoperative diagnosis: non-malignant (group I, $n=45$ ) and malignant thyroid disease (group II, $n=110$ ). Postoperative parameters (histology, complication rates) were assessed and compared between groups.

Results $91.1 \%$ of group I were histologically benign. $44.5 \%$ of group II harbored malignancy. Permanent hypoparathyroidism was documented in group I $(2.7 \%)$ and in group II $(1.4 \%, p=1.000)$. Wound infections were absent in group I but observed in group II $(0.9 \%, \mathrm{p}=1.000)$. Transient vocal cord palsy was recorded only in group I $(2.3 \%, 2 / 85$ vs. $0 / 177$ nerves at risk, $p=$ 0.104). Permanent vocal cord palsies were absent.

Conclusion Preoperative diagnoses were correct in over $90 \%$ of group I and in nearly $45 \%$ of group II. The high proportion of carcinomas in group II ruled out the issue of potential overtreatment. The risk of severe postoperative complications was equally low in both patient groups.
\end{abstract}

Keywords Endocrine $\cdot$ Pediatric thyroid surgery $\cdot$ Papillary thyroid carcinoma follicular thyroid carcinoma

\section{Introduction}

Electronic supplementary material The online version of this article (https://doi.org/10.1007/s00423-020-01896-x) contains supplementary material, which is available to authorized users.

Thomas J. Musholt

musholt@uni-mainz.de

1 Section of Endocrine Surgery, Department of General, Visceral and Transplantation Surgery, University Medical Center, Johannes Gutenberg University Mainz, Langenbeckstraße 1, 55131 Mainz, Germany

2 Department of General, Visceral and Transplantation Surgery, University Medical Center, Johannes Gutenberg University Mainz, Langenbeckstraße 1, 55131 Mainz, Germany

3 Institute for Medical Biometry, Epidemiology and Informatics, University Medical Center, Johannes Gutenberg-University Mainz, Langenbeckstraße 1, 55131 Mainz, Germany

4 Section of Pediatric Endocrinology, Center for Pediatrics, University Medical Center, Johannes Gutenberg University Mainz, Langenbeckstraße 1, 55131 Mainz, Germany
In children and adolescents, thyroid carcinoma is among the most frequently observed tumor entities of the endocrine system [1]. An increasing incidence was observed over the last decades [2-6]. In $90 \%$ of pediatric thyroid carcinoma, papillary thyroid carcinoma (PTC) is the underlying entity, which - in comparison with the adult population - presents more frequently with multifocal disease and metastases to regional neck lymph nodes [7-11]. Follicular thyroid carcinoma (FTC) and poorly differentiated thyroid carcinoma (PDTC) are relatively rare [7]. Medullary thyroid carcinoma (MTC) plays a key role in individuals suffering from multiple endocrine neoplasia (MEN) syndrome, whereas sporadic cases of MTC are infrequent $[4,8,12]$. Even thoughcompared with the adult population - the literature suggests that thyroid nodules in children and adolescents are more frequently associated with malignant disease [13, 14]; there is yet a risk of surgical overtreatment. Critical evaluation for surgery 
is required to fulfill the goal phrased by the American Thyroid Association in 2015, that is "to maintain the low diseasespecific mortality currently experienced by children with differentiated thyroid carcinoma (DTC)" and "to reduce potential complications resulting from therapy" [4]. Most important complications, which can result from pediatric thyroid surgery, are hypoparathyroidism, vocal cord palsy, or postoperative bleeding. Furthermore, wound infection or lymph fistula may occur.

Apart from careful preoperative selection of patients who should undergo surgery, the choice of the adequate resection strategy is essential. The American Thyroid Association recommends the performance of neck ultrasonography and fineneedle aspiration cytology (FNAC) for the evaluation of pediatric thyroid nodules [15]. However, in adult cohorts, as well as in children and adolescents, FNAC bears limitation for the assessment of follicular lesions and because of the new defined entity "noninvasive follicular thyroid neoplasm with papillary-like nuclear features" (NIFTP) even for papillary thyroid carcinoma [16]. Consequently, the true nature of a "suspicion nodule" remains undetermined in many cases preoperatively [15, 17-23].

This single center study analyzes the spectrum of indications for surgery and performed resection strategies and postoperative outcome in a cohort of children and young adults over a 13-year period. The aim of the study was to answer the questions if there is overtreatment for thyroid nodules (as measured by the number of actual carcinomas in individuals operated for suspected thyroid malignancy), and whether potential overtreatment leads to an increased rate of postoperative complications.

\section{Material and methods}

\section{Participants}

The study includes all thyroid operations performed in children and young adults at the University Medical Center (UMC) in the period from January 2005 to September 2018. Many children who were examined for thyroid disease and followed in the same time period in our clinic were not included in the study. The evaluation of thyroid nodules included thyroid specific laboratory analysis, repeated neck ultrasound by experienced examiners with assessment of risk factors (microcalcifications, echogenicity, perfusion, margins, diameter, growth, lymph nodes). The TIRADS classification was introduced in 2018 [24, 25]. Suspicious nodules were selected for FNAC, if the result would have impact on the indication of for surgery and/or the operative strategy. FNAC was completed by routine molecular genetic analysis for $B R A F$ and $R E T /$ $P T C$. In MEN 2 patients, the surgical strategy was based on the preoperative basal calcitonin level. The indication for the surgery was the result of comprehensive diagnostic work-up, as well as the detailed discussion with parents, cooperating pediatricians, endocrinologists, and colleagues from the nuclear medicine department (Fig. 1). All patients underwent routine pre- and postoperative laryngoscopy assessment at the Department of Otolaryngology, UMC Mainz, according to the recommendation of the German Association of Endocrine Surgeons (CAEK) guidelines for thyroid surgery in adults [26-28]. Oncological follow-up was performed as a cooperation between the Department of Pediatrics, Nuclear Medicine, and Surgery Departments.

\section{Surgery}

Although all surgeons of the Section of Endocrine Surgery of the Department of General, Visceral and Transplantation Surgery were involved in the pre- and postoperative patient care, $95.8 \%$ of operations were carried by one surgeon (> 19 years expertise in the field of endocrine surgery). Intraoperative frozen section was routinely used in cases with pre- or intraoperative suspected malignancy. Indications for surgery for nonmalignant thyroid disease in children were established according to the CAEK guidelines for the surgical treatment of benign thyroid diseases [28]. Lymph node dissection was performed according to the CAEK practice guidelines for the management of malignant thyroid disease in adults [27] as well as the ATA management guidelines for children with thyroid nodules and differentiated thyroid cancer [7]: lateral lymph node dissection was carried out in case of histologically proven lateral lymph node metastases and central lymph node dissection was performed either in therapeutic or in prophylactic intention, carefully weighing risk of postoperative morbidity with oncological advantages in the individual patient.

\section{Study design}

Cases were grouped according to the preoperative indication for surgery: group I, preoperative non-malignant diagnosis (including Graves' disease, symptomatic nodular goiter and autonomous thyroid nodules) and group II, preoperative malignant diagnosis (including suspected/preoperatively diagnosed differentiated thyroid carcinoma, suspected/preoperatively diagnosed medullary thyroid carcinoma, completion thyroidectomy for malignancy and prophylactic thyroidectomy in case of hereditary tumor syndromes). Primary endpoints were the postoperative complications transient/permanent vocal cord, transient/ permanent hypoparathyroidism, and the necessity of reoperation for bleeding, lymph fistula, or wound infection. Preoperative parameters (FNAC, molecular diagnostics, indication for surgery), intraoperative management, and histological results (primary/secondary diagnosis, TNM classification and oncological outcome) were assessed. Standard postoperative laboratory 


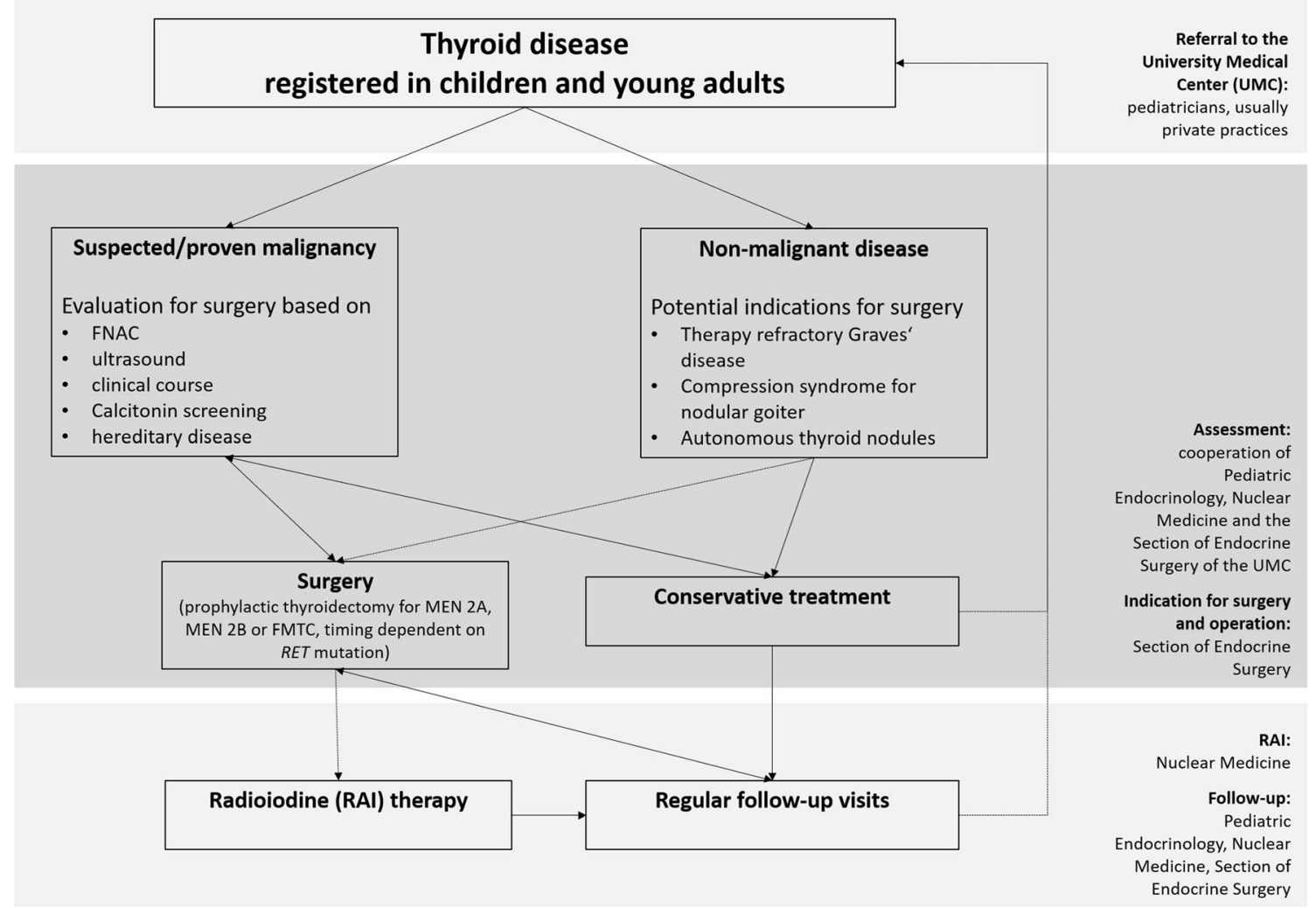

Fig. 1 Flow chart: decision-making towards thyroid surgery versus conservative treatment in children and young adults at the University Medical Center Mainz

investigation included parathyroid hormone and serum calcium levels. The postoperative complication "hypoparathyroidism" (parathyroid hormone level below $10 \mathrm{pg} / \mathrm{ml}$ ) was defined permanent, if persisting for $>6$ months postoperatively. Unilateral thyroid operations were excluded from the analysis of postoperative hypoparathyroidism.

\section{Statistical analysis}

Data were documented and described using Microsoft Excel (Microsoft Corporation, Redmond, USA). Median and standard deviation (SD) are presented, when suitable. The description of histological results includes an overview over different age groups ( $<6$ years, $6-10$ years, $10-14$ years, $14-16$ years, and 16-20 years of age). Further analyses were performed using the IBM Statistical Package for Social Science (SPSS) version 23 (IBM Corporation, Armonk, USA). For postoperative complications, the risk ratio (RR) was calculated, comparing the chance to remain free from complication for the analyzed groups I and II. If procurable, the odds ratio (OR) was additionally calculated. Ninety-five percent confidence intervals $(\mathrm{CI})$ for RR and OR were indicated. Fisher's exact test was performed to analyze, if preoperative diagnosis and postoperative complications are independent.

\section{Results}

Of a total of 155 operations, $75.5 \%$ were performed in female patients (Table 1). Mean patient age was 14 years (range 3-20 years, Table 1). In $11.6 \%$, previous thyroid surgery was registered; $70.6 \%$ (12) were carried out in our center. In $14.2 \%$, genetic disorders affecting the thyroid gland were recorded (Table 1). Those were in $40.9 \%$ MEN2A, RET codon 634 mutation (9), in $18.2 \%$ Pendred syndrome (4), in $18.2 \%$ PTEN hamartoma tumor syndrome, in $9.1 \%$ (2) TPO gene mutation (hormone synthesis deficiency), in 9.1\% MEN2, codon 804 mutation (2) and in $4.5 \%$ (1) DICER1 mutation. Preoperative FNAC was performed in $27.1 \%$ of cases (Table 1). There were Bethesda category II ("benign") in $54.8 \%$ (23). Bethesda category V ("suspicious for malignancy") was diagnosed in $16.7 \%$ (7), and Bethesda category IV ("suspicious for follicular neoplasm") and Bethesda category VI ("malignancy") were diagnosed in equally $9.5 \%$ (4). Independent from the cytological result, a molecular assessment of BRAFV600E mutation, as a highly sensitive indicator of the presence of papillary thyroid carcinoma [29], was conducted for $90.5 \%$ of FNAC aspirates (38). $10.5 \%$ of analyzed cases harbored BRAFV600E mutation. 
Table 1 Descriptive statistics of cohort of children and young adults

\begin{tabular}{|c|c|c|c|}
\hline & $\begin{array}{l}\text { Group } 1 \text { (preoperative } \\
\text { nonmalignant diagnosis) } n=45\end{array}$ & $\begin{array}{l}\text { Group } 2 \text { (preoperative } \\
\text { malignant diagnosis) } n=110\end{array}$ & $\begin{array}{l}\text { Total } \\
n=155\end{array}$ \\
\hline Age [years] (median $\pm \mathrm{SD})$ & $15 \pm 2.8$ & $14 \pm 3.7$ & $15 \pm 3.6$ \\
\hline Sex ratio female:male $(N)$ & $40: 5$ & $77: 33$ & $117: 38$ \\
\hline Previous thyroid surgery $(N)$ & 0 & 18 & 18 \\
\hline Hereditary thyroid disease $(N)$ & 2 & 20 & 22 \\
\hline Preoperative FNAC $(N)$ & 1 & 41 & 42 \\
\hline Operation time [minutes] (median $\pm \mathrm{SD})$ & $113 \pm 37$ & $107.5 \pm 87$ & $109 \pm 70$ \\
\hline Hospitalization time [days] (median $\pm \mathrm{SD})$ & $4 \pm 3.2$ & $4 \pm 1.9$ & $4 \pm 2.3$ \\
\hline \multicolumn{4}{|l|}{ Type of operation } \\
\hline Total thyroidectomy $(N)$ & 40 & 60 & 100 \\
\hline Subtotal Thyroidectomy $(N)$ & 0 & 1 & 1 \\
\hline Partial Thyroidectomy $(N)$ & 0 & 1 & 1 \\
\hline Lobectomy $(N)$ & 1 & 45 & 46 \\
\hline Lymph node dissection only $(N)$ & 0 & 7 & 7 \\
\hline Lymph node dissection as part of Thyroidectomy $(N)$ & 1 & 38 & 39 \\
\hline Bilateral neck surgery $(N)$ & 41 & 72 & 113 \\
\hline Parathyroid replantation $(N)$ & 14 & 47 & 61 \\
\hline Malignancy in histology $(N)$ & 4 & 49 & 53 \\
\hline Nerves at risk $(N)$ & 85 & 177 & 262 \\
\hline \multicolumn{4}{|l|}{ Complications } \\
\hline Transient hypoparathyroidism $(N)$ & 14 & 24 & 38 \\
\hline Permanent hypoparathyroidism $(N)$ & 1 & 1 & 2 \\
\hline Reoperation for wound infection $(N)$ & 0 & 1 & 1 \\
\hline Reoperation for lymph fistula $(N)$ & 0 & 1 & 1 \\
\hline Transient vocal cord palsy $(N)$ & 2 & 0 & 2 \\
\hline
\end{tabular}

\section{Surgical management}

Mean operation time was 129 (range 28-522 min, Table 1). Mean hospitalization time was 4 days (range 2-13 days). In $64.5 \%$, total thyroidectomy was performed. Lobectomy was carried out in $29.7 \%$. Subtotal and partial thyroidectomies were performed in equally $0.6 \%$ (Table 1 ). Seven patients (4.5\%) underwent secondary lymph node dissection following thyroidectomy for persistent lymph node metastases. The overall rate of parathyroid autotransplantation was $39.4 \%$ (Table 1). Calculated for bilateral thyroid surgery, this rate was $50.4 \%$ (57/113). Autotransplantation of parathyroid glands was necessary, e.g., as a consequence of central lymph node dissection, which, as a part of the operative technique, requires the removal of the lower parathyroid glands. Lymphadenectomy was carried out in $29.0 \%$ (46) of cases, in $50.2 \%$ (24) as central lymph node dissection (=compartment $1 \mathrm{a}$ and $1 \mathrm{~b}$ [30]). In $17.4 \%$ (8), unilateral lateral neck dissection was performed together with central lymph node dissection (=compartment $1 \mathrm{a}, 1 \mathrm{~b}$, and 2 or $3[30]$ ), and in $2.2 \%$ (1) bilateral lateral lymph node resection and central lymph node dissection (=compartment $1 \mathrm{a}, 1 \mathrm{~b}, 2$, and 3 [30]). The remaining cases included selective lymph node dissection $(13.0 \%$ (6)) and lymph node biopsy for diagnostic reasons $(15.2 \%, 7)$.

\section{Histological entities}

In $34.2 \%$ (53/155) of all cases, malignant diagnoses were present in final histology (Fig. 2, Table 2). 62.3\% (33) of malignant diagnoses were detected in female patients. $79.2 \%$ (42) of malignant diagnoses were histologically PTC (T1a 16.7\% (7), T1b 11.9\% (5), T2 42.9\% (18), T3 23.8\% (10), and T4a in $4.8 \%$ (2)). Multifocal PTC was diagnosed in $26.2 \%$ (11). Lymph node status was distributed as follows: $\mathrm{Nx}$ in 11 cases $(26.2 \%)$, N0 in 13 cases $(31.0 \%)$, and N1a and N1b in equally 9 cases (21.4\%). In 7 of 42 PTC cases, concomitant thyroiditis was diagnosed, $7.1 \%$ (3) with Graves' disease and $9.5 \%$ (4) Hashimoto's thyroiditis. Loco-regional recurrence (lymph node metastases) was registered in one case of PTC.

In $13.2 \%$ (7), the histological diagnosis was MTC. Six tumors underwent molecular analysis, which in all cases revealed MEN2A Codon 634 mutation. All cases of surgery 


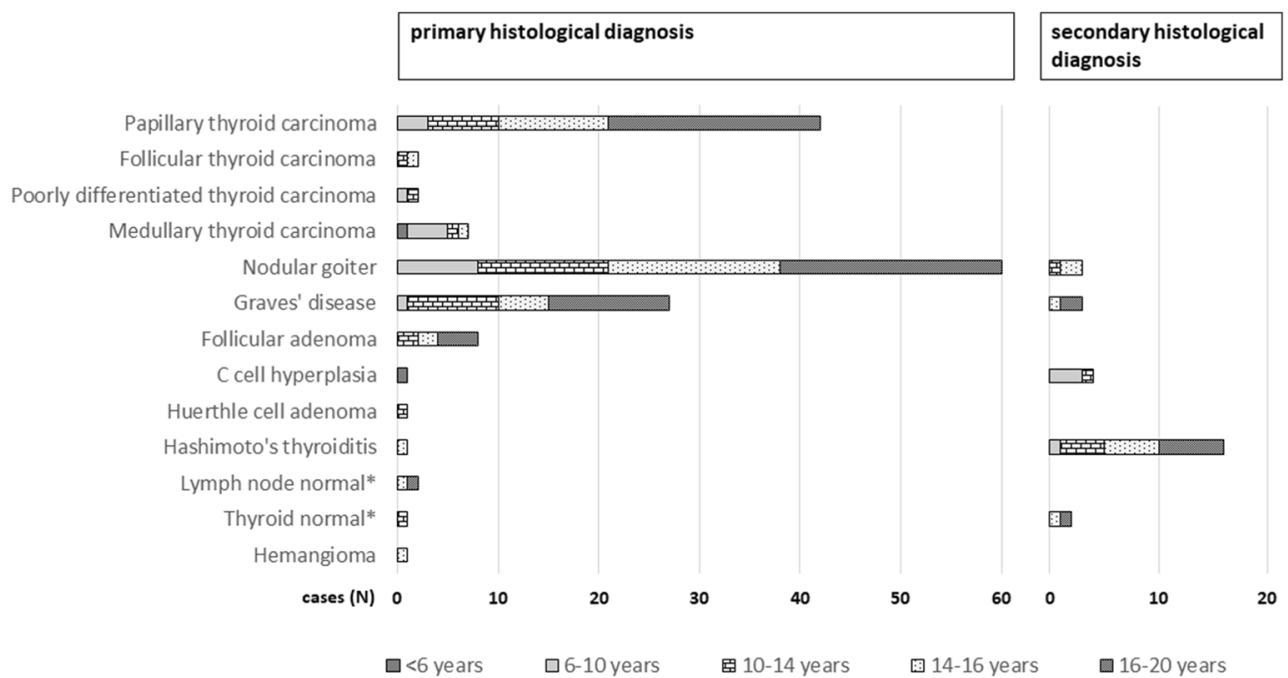

Fig. 2 Absolute distribution of final histological diagnoses. Patient age is indicated by bar pattern. The most prevalent primary histological diagnoses were multinodular goiter, papillary thyroid carcinoma and Graves' disease. Most common associations of primary and secondary histological diagnoses were nodular goiter/Hashimoto's thyroiditis (12

were the primary operations for these patients. Median of preoperative calcitonin level was $46.8 \mathrm{pg} / \mathrm{ml}$ (mean $44.5 \pm$ 21). Postoperatively a stable calcitonin value $<2 \mathrm{pg} / \mathrm{ml}$ was achieved in all cases. Among the MTCs, there were 6 pTla tumors, which were, except for $1 \mathrm{Nx}$ tumor, N0 entities. One tumor was T3 stage, N1b. 50\% of hereditary MTC cases had concomitant C-cell hyperplasia (3).

There were 2 cases of FTC (3.8\%), one was T2 stage that received completion thyroidectomy after lobectomy. The second case was T1b stage, which was initially treated with thyroidectomy. Both tumors were Nx diagnoses without recurrence. There were two cases of PDTC in the cohort, of which one was treated with lobectomy in the first place, receiving completion thyroidectomy. The other case initially was treated with total thyroidectomy. Recurrence was not registered.

In $65.8 \%$, benign entities were diagnosed (102). $58.8 \%$ were nodular goiter (60). In $20.0 \%$ (12) of cases with nodular goiter, lymphocytic thyroiditis Hashimoto was recorded as a secondary diagnosis. Graves' disease was diagnosed in $26.5 \%$ (27). C-cell hyperplasia and lymphocytic thyroiditis were diagnosed in equally $1.0 \%$ of cases (1). Normal lymph node tissue was registered in two of 102 cases and normal thyroid in one of 102 cases, with the operations being performed as completion resection following previously diagnosed malignant disease.

\section{Postoperative complications}

Median follow-up time was 42 postoperative days (mean 517, range 1-4985 days). The immediate postoperative vocal cord assessment showed a palsy in $0.76 \%(2 / 262$ nerves at risk (NAR), Table 1). For this analysis, one patient was excluded cases), papillary thyroid carcinoma/Hashimoto's thyroiditis (4 cases), papillary thyroid carcinoma/Graves' disease (3 cases) and medullary thyroid carcinoma/C cell hyperplasia ( 3 cases). $*$ Primary diagnosis: result from completion thyroidectomy

for preoperative bilateral vocal cord palsy. For two patients, postoperative laryngoscopy was not performed. There were no long-term vocal cord palsies registered. One patient with an early postoperative vocal cord dysfunction did not take part in long-term laryngoscopy control.

Postoperative transient hypoparathyroidism was detected in $33.6 \%(38 / 113)$ of bilateral operations. Permanent hypoparathyroidism was detected in $1.9 \%$ (2/106). However, seven patients did not take part in long-term follow-up, of these, six cases with immediate, postoperative hypoparathyroidism.

$7.8 \%$ (12) of registered cases required a secondary operation. One was for wound infection, one for lymph fistula, and ten for oncologic reasons. Of the latter, eight were completion thyroidectomies, and two were for suspected recurrence of PTC. There were no reoperations for postoperative bleeding.

\section{Preoperative diagnoses}

Nonmalignant diagnoses were established preoperatively in $29.0 \%$ (45), referred to as group I (Table 1, Table 2). These were in $77.8 \%$ Graves' disease (35), in $15.6 \%$ compression syndrome for nodular goiter (7) and in $6.7 \%$ autonomous thyroid nodules (3). Diagnosis of benign thyroid disease was histologically confirmed in $91.1 \%$ (41, Fig. 3). Indication for surgery was in $71.0 \%$ (110) preoperatively suspected/verified malignant diagnoses (group II). Indications were distributed as follows: $70.0 \%$ (77) suspected DTC/intended exclusion of malignancy, 9.1\% (10) verified DTC, 9.1\% (10) prophylactic thyroidectomy in hereditary disease, $1.8 \%$ (2) suspected/ verified MTC, $3.6 \%$ (4) nodular goiter following radiochemotherapy, and $6.4 \%$ (7) completion surgery. 
Table 2 Preoperative indication for surgery and postoperative final histology results

\begin{tabular}{|c|c|c|c|}
\hline & $\begin{array}{l}\text { Group } 1 \text { (preoperative } \\
\text { nonmalignant diagnosis) } n=45\end{array}$ & $\begin{array}{l}\text { Group } 2 \text { (preoperative } \\
\text { malignant diagnosis) } n=110\end{array}$ & Total $n=155$ \\
\hline \multicolumn{4}{|l|}{ Indication for surgery } \\
\hline Graves' disease & 35 & 0 & 35 \\
\hline Compression syndrome & 7 & 0 & 7 \\
\hline Autonomous thyroid nodule & 3 & 0 & 3 \\
\hline Suspicion for differentiated thyroid carcinoma & 0 & 77 & 77 \\
\hline Suspicion for medullary thyroid carcinoma & 0 & 2 & 2 \\
\hline Differentiated thyroid carcinoma (proven) & 0 & 10 & 10 \\
\hline Prophylactic thyroidectomy & 0 & 10 & 10 \\
\hline Nodular goiter after chemo-/radiotherapy & 0 & 4 & 4 \\
\hline Completion thyroidectomy & 0 & 7 & 7 \\
\hline \multicolumn{4}{|l|}{ Postoperative final histology_-primary diagnosis } \\
\hline Benign diagnoses & 41 & 61 & 102 \\
\hline Nodular goiter & 11 & 49 & 60 \\
\hline Graves' disease & 27 & 0 & 27 \\
\hline Follicular adenoma & 3 & 5 & 8 \\
\hline Hashimoto's thyroiditis & 0 & 1 & 1 \\
\hline Normal lymph node tissue & 0 & 2 & 2 \\
\hline Normal thyroid tissue & 0 & 1 & 1 \\
\hline C-cell hyperplasia & 0 & 1 & 1 \\
\hline Huerthle cell adenoma & 0 & 1 & 1 \\
\hline Hemangioma thyroid & 0 & 1 & 1 \\
\hline Malignant diagnoses & 4 & 49 & 53 \\
\hline Papillary thyroid carcinoma & 4 & 38 & 42 \\
\hline Follicular thyroid carcinoma & 0 & 2 & 2 \\
\hline Medullary thyroid carcinoma & 0 & 7 & 7 \\
\hline Poorly differentiated thyroid carcinoma & 0 & 2 & 2 \\
\hline \multicolumn{4}{|l|}{ Postoperative final histology—secondary diagnosis } \\
\hline Nodular goiter & 2 & 2 & 4 \\
\hline Graves' disease & 3 & 0 & 3 \\
\hline Hashimoto's thyroiditis & 3 & 13 & 16 \\
\hline C-cell hyperplasia & 0 & 4 & 4 \\
\hline Normal thyroid tissue & 0 & 1 & 1 \\
\hline No secondary diagnosis & 37 & 90 & 127 \\
\hline
\end{tabular}

Diagnosis of thyroid carcinoma was confirmed by final histology in $44.5 \%$ of cases (49, Fig. 3).

\section{Postoperative complications in relation to preoperative diagnosis}

In group I, transient hypoparathyroidism was present in $34.1 \%$ (14/41). In group II, there were $33.3 \%$ of transient hypoparathyroidism (24/72, RR 1.012 (0.769-1.332), $p=1.000$, supplementary Table 1). In group I, there was one case of permanent hypoparathyroidism $(1 / 36,2.7 \%)$. One case was registered with permanent hypoparathyroidism $(1 / 70,1.4 \%)$ in group II. Of group I, five cases of transient hypoparathyroidism were lost to follow-up, and one of group II.

Whereas in group I, reoperation for postoperative complication was not necessary, in group II, reoperation was performed in one case $(0.9 \%)$ for wound infection (RR 0.991 (0.973-1.009), $p=1.000)$, and also in $0.9 \%$ for lymph fistula (RR 0.991 (0.973-1.009), $p=1.000$, Fig. 4).

Two transient vocal cord palsies were registered in group I (2/85 NAR, 2.3\%), whereas in group II, there was none (RR 1.024 (0.991-1.058), $p=0.104$, Fig. 4). In group I, postoperative laryngoscopy was performed in all cases. One of the two transient vocal cord palsies had recovered in a long-term laryngoscopy control. The second case did not take part in 


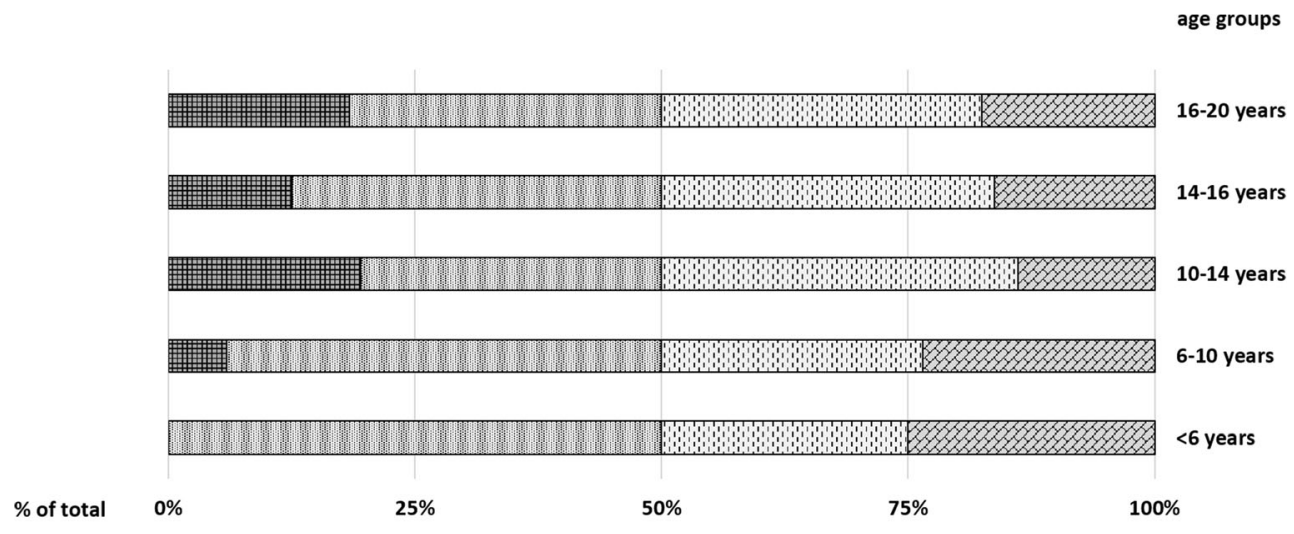

田 indication: preoperative non-malignant diagnosis (group I)

Thistology: benign

Fig. 3 Relative distribution of preoperatively assumed diagnoses and final histological results. In group II, which includes all operations for preoperatively suspected/proven malignancy, final histology revealed the presence of malignant entities in $44.5 \%$ of cases $(<6$ years $50.0 \%, 6$

follow-up. Since the intraoperative nerve monitoring verified intact function of the recurrent laryngeal nerve in these cases, a temporary paresis is plausible. For two patients without symptoms of vocal cord palsy, belonging to group II, postoperative laryngoscopy was not performed.

\section{Discussion}

For young children, the literature reported no significant differences in the distribution of thyroid carcinoma between sexes, whereas in young adults, a significant gynaecotropism (5:1) was observed [3-5]. The distribution between the sexes in the present analysis is in line with these results, as the majority of patients diagnosed with thyroid carcinoma was female $(62.3 \%$, mean cohort age 14). The overall percentage of malignant entities on final histology was relatively high $(34.2 \%)$, which can be explained by the preferred referral of patients with strong

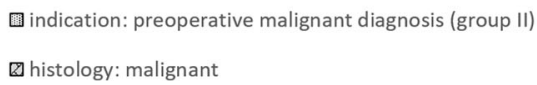

10 years $53.3 \%, 10-14$ years $43.5 \%, 14-16$ years $38.7 \%, 16-20$ years $46.2 \%)$. In group I, preoperatively established nonmalignant diagnoses were histologically confirmed in $91.1 \%$ (6-10 years $100 \%, 10-14$ years $100 \%, 14-16$ years $88.9 \%, 16-20$ years $85.7 \%$ )

suspicion for thyroid malignancy and prediagnosed hereditary tumor syndromes to the UMC Mainz. The underlying histological entity was mainly PTC $(79.2 \%$, Fig. 2$)$. In group II-comprising operations for suspected/verified thyroid malignancy - final histology revealed the presence of malignant diagnoses in nearly half of all cases (44.5\%). This result was consistent in different age subgroups (Fig. 3). The remaining $55.5 \%$ of group II harbored benign entities. These include cases of completion thyroidectomy ( 7 cases) and cases of prophylactic thyroidectomy for hereditary disease (10 cases), preempting the development of malignant disease. From other cohorts reported by specialized institutions operating children for the main indications of suspected malignancy and therapy-refractory Graves' disease, similar proportions of malignancy were reported as, e.g., in 2011 by Scholz et al. 36\% [31] and Wood et al. $37 \%$ [32], in 2008 by the Canadian Pediatric Thyroid Nodule (CaPTN) Study Group 43\% [33] and in 2019 by Baumgarten et al. 39\% [34].

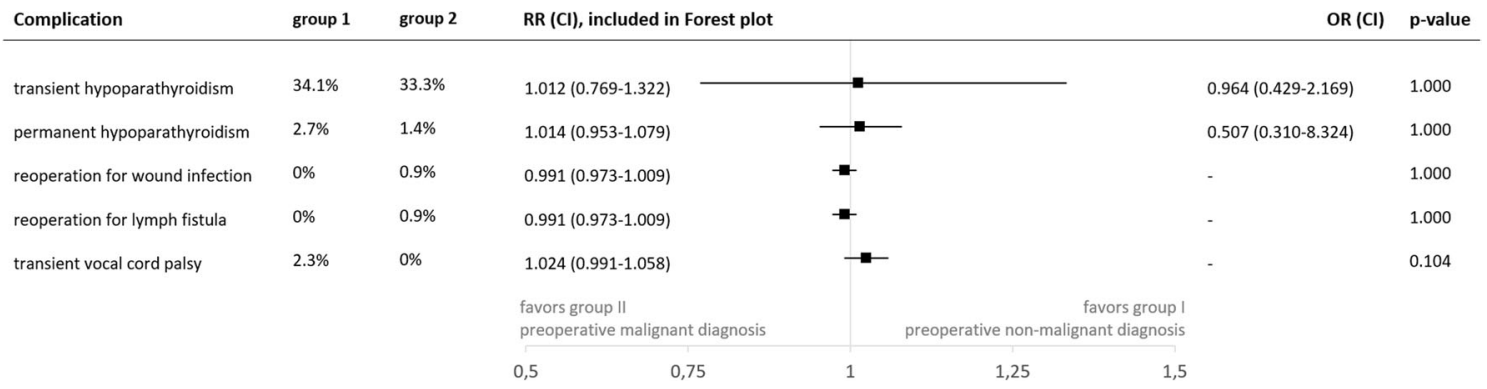

Fig. 4 Postoperative complications in relation to preoperative diagnosis. The indication for surgery (group I: preoperative non-malignant diagnosis, group II: preoperative malignant diagnosis) did not significantly influence the occurrence of postoperative complications. Abbreviations: $\mathrm{RR} \mathrm{R}^{-}$-risk ratio, OR odds ratio, CI 95\%-confidence interval 
In children and adolescents, complication rates were shown to be higher than in the adult population, with particularly high complication rates at young age $<6$ years $[35,36]$. An analysis of the Swedish National Registry showed that for total thyroidectomy in children, the rate of permanent hypoparathyroidism reached $7.3 \%$ [37]. In the present analysis, median patient age was similar as in the aforementioned study. Yet, permanent hypoparathyroidism was observed only in $1.9 \%$, even though cases of intentional parathyroidectomy for locally advanced thyroid carcinoma were not excluded from analysis. Comparably low rates of permanent hypoparathyroidism were also reported by other specialized centers $[31,32,38]$. Transient hypoparathyroidism was observed in $33.6 \%$ of bilateral thyroid operations in the present analysis but recovered in the vast majority of cases $(1.9 \%$ permanent hypoparathyroidism). In a series of 464 pediatric patients with a similar median patient age of 15 years (36\% histologically PTC and $3 \%$ MTC), a rate of transient hypoparathyroidism was registered in $37 \%$, and $0.6 \%$ with permanent hypoparathyroidism [34]. In the present study, an underlying restoration period following parathyroid autotransplantation appears plausible for this observation. In the literature, children with the diagnosis of Graves' disease were shown to harbor a higher risk for transient hypoparathyroidism [38]. This study illustrates, that the risk of transient hypoparathyroidism in group I, consisting to $77.8 \%$ of cases with therapy refractory Graves' disease, was similar as in group II, which included operations for preoperatively suspected/verified malignant diagnoses (Fig. 4). These results, however, remain above the $6 \%$ of transient hypoparathyroidism documented by Sherman et al. in a cohort of children $<18$ years of age suffering from Graves' disease [39]. Postoperative bleeding requiring secondary surgery did not occur in the present patient cohort, which remains below the incidence of $0.1-2.1 \%$, described in the adult population $[40,41]$.

$11.6 \%$ of the present cohort were thyroid reoperations. Thyroid reoperations in the adult population were reported to be associated with transient injury of the recurrent laryngeal nerve in up to $12.5 \%$ and permanent lesions in $3.8 \%$ [42]. In the present study, only one transient vocal cord palsy $(2.3 \%)$ was observed during the regularly performed postoperative laryngoscopy. Also, other specialized centers reported similarly favorable results in cohorts of children and adolescents [31, 32].

In this analysis, there were no significant differences in the postoperative complication rates between the patient groups defined by preoperatively established diagnoses. As a consequence, a potential — but yet highly debatable — overtreatment observed in group II did not lead to a significant increase in postoperative complications. Of note is, that in the present study, patients with thyroid malignancy were treated according to the CAEK guidelines [27] and therefore underwent a more radical surgical approach than in other countries: e.g., the ATA management guidelines for children with thyroid nodules and differentiated thyroid cancer allow for near-total thyroidectomy (instead of thyroidectomy) in order to prevent injury of the recurrent laryngeal nerve or parathyroid insufficiency in case of, e.g., papillary thyroid carcinoma [7]. Still, the low complication rate in the present cohort affirms an adequate application of surgical management and was associated with an advantageous oncological outcome in the shortterm follow-up (recurrence in only 1 of 53 patients with malignant thyroid disease). Of course, the mean follow-up of 1.4 years does not allow for a meaningful evaluation of disease-free and overall survival since thyroid cancer can recur after long time interval. Both the CAEK and the ATA leave it to the treating surgeons to decide, whether their surgical skills justify the performance of a prophylactic central lymphadenectomy, which potentially contributes to a reduction of redo surgery and an improved disease-free survival [7, 27]. In line with this, for thyroid operations in children, a treatment by specialized high-volume surgeons was recommended in the literature [34-36, 43]. To provide the background for an adequate surgical management, a developed network of pediatric endocrinology, pathology, endocrine surgery, and nuclear medicine holds importance.

\section{Conclusion}

To provide the background for an adequate surgical management of pediatric thyroid disease, the preoperative assessment is of crucial importance, underlining the necessity of a developed network of pediatric endocrinology, pathology, endocrine surgery, and nuclear medicine. Critical indication for surgery allows for a high portion of actual carcinomas in cohorts of children and adolescents undergoing thyroid surgery. Postoperative complications can be kept to a minimum in specialized centers, independent from indication for surgery (malignant vs. nonmalignant thyroid disease).

Authors' contributions Study conception and design: TJ Musholt and JI Staubitz. Acquisition of data: JI Staubitz and J Bode. Analysis and interpretation of data: JI Staubitz, A Poplawski, TJ Musholt and F Watzka. Drafting of manuscript: JI Staubitz and TJ Musholt. Critical revision of manuscript: TJ Musholt, F Watzka, H Lang and J Pohlenz.

Funding information Open Access funding provided by Projekt DEAL.

\section{Compliance with ethical standards}

Conflict of interest The authors declare that they have no conflict of interest. All procedures performed in studies involving human participants were in accordance with the ethical standards of the institutional and national research committee and with the 1964 Helsinki declaration and its later amendments or comparable ethical standards. Informed 
consent was obtained from all individual participants included in the study. The study was approved by the local ethical committee.

Open Access This article is licensed under a Creative Commons Attribution 4.0 International License, which permits use, sharing, adaptation, distribution and reproduction in any medium or format, as long as you give appropriate credit to the original author(s) and the source, provide a link to the Creative Commons licence, and indicate if changes were made. The images or other third party material in this article are included in the article's Creative Commons licence, unless indicated otherwise in a credit line to the material. If material is not included in the article's Creative Commons licence and your intended use is not permitted by statutory regulation or exceeds the permitted use, you will need to obtain permission directly from the copyright holder. To view a copy of this licence, visit http://creativecommons.org/licenses/by/4.0/.

\section{References}

1. Massimino M, Evans DB, Podda M, Spinelli C, Collini P, Pizzi N, Bleyer A (2018) Thyroid cancer in adolescents and young adults. Pediatr Blood Cancer 65(8):e27025. https://doi.org/10.1002/pbc. 27025

2. Vergamini LB, Frazier AL, Abrantes FL, Ribeiro KB, RodriguezGalindo C (2014) Increase in the incidence of differentiated thyroid carcinoma in children, adolescents, and young adults: a populationbased study. J Pediatr 164(6):1481-1485. https://doi.org/10.1016/j. jpeds.2014.01.059

3. Hogan AR, Zhuge Y, Perez EA, Koniaris LG, Lew JI, Sola JE (2009) Pediatric thyroid carcinoma: incidence and outcomes in 1753 patients. J Surg Res 156(1):167-172. https://doi.org/10. 1016/j.jss.2009.03.098

4. Francis GL, Waguespack SG, Bauer AJ, Angelos P, Benvenga S, Cerutti JM, Dinauer CA, Hamilton J, Hay ID, Luster M, Parisi MT, Rachmiel M, Thompson GB, Yamashita S, American Thyroid Association Guidelines Task Force (2015) Management guidelines for children with thyroid nodules and differentiated thyroid cancer. Thyroid 25(7):716-759. https://doi.org/10.1089/thy.2014.0460

5. Wu XC, Chen VW, Steele B, Roffers S, Klotz JB, Correa CN, Carozza SE (2003) Cancer incidence in adolescents and young adults in the United States, 1992-1997. J Adolesc Health 32(6): 405-415

6. Bernier MO, Withrow DR, Berrington de Gonzalez A, Lam CJK, Linet MS, Kitahara CM, Shiels MS (2019) Trends in pediatric thyroid cancer incidence in the United States, 1998-2013. Cancer 125(14):2497-2505. https://doi.org/10.1002/cncr.32125

7. Francis G, Waguespack SG, Bauer AJ, Angelos P, Benvenga S, Cerutti J, Dinauer CA, Hamilton J, Hay ID, Luster M, Parisi MT, Rachmiel M, Thompson GB, Yamashita S, American Thyroid Association Guidelines Task Force (2015) Management guidelines for children with thyroid nodules and differentiated thyroid cancer the American Thyroid Association Guidelines Task Force on pediatric thyroid cancer. Thyroid. 25:716-759. https://doi.org/10.1089/ thy.2014.0460

8. Demidchik YE, Demidchik EP, Reiners C, Biko J, Mine M, Saenko VA, Yamashita S (2006) Comprehensive clinical assessment of 740 cases of surgically treated thyroid cancer in children of Belarus. Ann Surg 243(4):525-532. https://doi.org/10.1097/01.sla. 0000205977.74806.0b

9. Popovtzer A, Shpitzer T, Bahar G, Feinmesser R, Segal K (2006) Thyroid cancer in children: management and outcome experience of a referral center. Otolaryngol Head Neck Surg 135(4):581-584. https://doi.org/10.1016/j.otohns.2006.04.004
10. Machens A, Lorenz K, Nguyen Thanh P, Brauckhoff M, Dralle H (2010) Papillary thyroid cancer in children and adolescents does not differ in growth pattern and metastatic behavior. J Pediatr 157(4): 648-652. https://doi.org/10.1016/j.jpeds.2010.04.026

11. Wada N, Sugino K, Mimura T, Nagahama M, Kitagawa W, Shibuya H, Ohkuwa K, Nakayama H, Hirakawa S, Rino Y, Masuda M, Ito K (2009) Pediatric differentiated thyroid carcinoma in stage I: risk factor analysis for disease free survival. BMC Cancer 9:306. https://doi.org/10.1186/1471-2407-9-306

12. Harness JK, Thompson NW, McLeod MK, Pasieka JL, Fukuuchi A (1992) Differentiated thyroid carcinoma in children and adolescents. World J Surg 16(4):547-553 discussion 553-544

13. Hung W (1999) Solitary thyroid nodules in 93 children and adolescents. A 35-years experience. Horm Res 52(1):15-18. https://doi. org/10.1159/000023426

14. Gupta A, Ly S, Castroneves LA, Frates MC, Benson CB, Feldman HA, Wassner AJ, Smith JR, Marqusee E, Alexander EK, Barletta J, Doubilet PM, Peters HE, Webb S, Modi BP, Paltiel HJ, Kozakewich H, Cibas ES, Moore FD Jr, Shamberger RC, Larsen PR, Huang SA (2013) A standardized assessment of thyroid nodules in children confirms higher cancer prevalence than in adults. J Clin Endocrinol Metab 98(8):3238-3245. https://doi.org/10.1210/ jc. 2013-1796

15. Rossi ED, Martini M, Cenci T, Capodimonti S, Larocca LM (2017) The role of thyroid FNA cytology in pediatric malignant lesions: an overview of the literature. Cancer Cytopathol 125(8):594-603. https://doi.org/10.1002/cncy.21884

16. Staubitz JI, Musholt TJ (2019) Individualization of the surgical procedure in response to overdiagnosis and overtreatment in differentiated thyroid carcinomas. Pathologe 40(Suppl 3):342-346. https://doi.org/10.1007/s00292-019-00699-2

17. Alonso N, Lucas A, Salinas I, Castella E, Sanmarti A (2003) Frozen section in a cytological diagnosis of thyroid follicular neoplasm. Laryngoscope 113(3):563-566. https://doi.org/10.1097/00005537200303000-00031

18. Bollig CA, Lesko D, Gilley D, Dooley LM (2018) The futility of intraoperative frozen section in the evaluation of follicular thyroid lesions. Laryngoscope 128:1501-1505. https://doi.org/10.1002/ lary. 26937

19. LiVolsi VA, Baloch ZW (2005) Use and abuse of frozen section in the diagnosis of follicular thyroid lesions. Endocr Pathol 16(4): 285-293

20. Carling T, Udelsman R (2005) Follicular neoplasms of the thyroid: what to recommend. Thyroid 15(6):583-587. https://doi.org/10. 1089/thy.2005.15.583

21. Kennedy JM, Robinson RA (2016) Thyroid frozen sections in patients with preoperative FNAs: review of surgeons' preoperative rationale, intraoperative decisions, and final outcome. Am J Clin Pathol 145(5):660-665. https://doi.org/10.1093/ajcp/aqw042

22. Alkhars A, Abouzayd M, RoufCE, Lardy H, Bakhos D, PondavenLetourmy S, Moriniere S, Lescanne E (2018) Pediatric thyroid surgery: experience in 75 consecutive thyroidectomies. Eur Arch Otorhinolaryngol 276:217-222. https://doi.org/10.1007/s00405018-5188-9

23. Pittock S (2018) Thyroid nodules in children. In: Gharib H (ed) Thyroid nodules. Contemporary Endocrinology. Humana Press, Cham. https://doi.org/10.1007/978-3-319-59474-3_14

24. Russ G, Bonnema SJ, Erdogan MF, Durante C, Ngu R, Leenhardt L (2017) European thyroid association guidelines for ultrasound malignancy risk stratification of thyroid nodules in adults: the EUTIRADS. Eur Thyroid J 6(5):225-237. https://doi.org/10.1159/ 000478927

25. Lim-Dunham JE, Toslak IE, Reiter MP, Martin B (2019) Assessment of the American College of Radiology Thyroid Imaging Reporting and Data System for thyroid nodule 
malignancy risk stratification in a pediatric population. AJR Am J Roentgenol 212(1):188-194. https://doi.org/10.2214/ajr.18.20099

26. Musholt TJ, Clerici T, Dralle H, Frilling A, Goretzki PE, Hermann MM, Kussmann J et al (2011) German Association of Endocrine Surgeons practice guidelines for the surgical treatment of benign thyroid disease. Langenbeck's Arch Surg 396(5):639-649. https:// doi.org/10.1007/s00423-011-0774-y

27. Dralle H, Musholt TJ, Schabram J, Steinmuller T, Frilling A, Simon D, Goretzki PE et al (2013) German Association of Endocrine Surgeons practice guideline for the surgical management of malignant thyroid tumors. Langenbeck's Arch Surg 398(3):347-375. https://doi.org/10.1007/s00423-013-1057-6

28. Musholt TJ, Bockisch A, Clerici T, Dotzenrath C, Dralle H, Goretzki PE, Hermann M et al (2018) Update of the S2k guidelines : surgical treatment of benign thyroid diseases. Chirurg 89(9):699709. https://doi.org/10.1007/s00104-018-0653-y

29. Paschke R, Cantara S, Crescenzi A, Jarzab B, Musholt TJ, Sobrinho Simoes M (2017) European thyroid association guidelines regarding thyroid nodule molecular fine-needle aspiration cytology diagnostics. Eur Thyroid J 6(3):115-129. https://doi.org/10.1159/ 000468519

30. Musholt TJ (2014) Classification of locoregional lymph nodes in medullary and papillary thyroid cancer. Langenbeck's Arch Surg 399(2):217-223. https://doi.org/10.1007/s00423-013-1146-6

31. Scholz S, Smith JR, Chaignaud B, Shamberger RC, Huang SA (2011) Thyroid surgery at Children's Hospital Boston: a 35-year single-institution experience. J Pediatr Surg 46(3):437-442. https:// doi.org/10.1016/j.jpedsurg.2010.09.009

32. Wood JH, Partrick DA, Barham HP, Bensard DD, Travers SH, Bruny JL, McIntyre RC Jr (2011) Pediatric thyroidectomy: a collaborative surgical approach. J Pediatr Surg 46(5):823-828. https:// doi.org/10.1016/j.jpedsurg.2011.02.013

33. The Canadian Pediatric Thyroid Nodule Study (2008) An evaluation of current management practices. J Pediatr Surg 43(5):826830. https://doi.org/10.1016/j.jpedsurg.2007.12.019

34. Baumgarten HD, Bauer AJ, Isaza A, Mostoufi-Moab S, Kazahaya K, Adzick NS (2019) Surgical management of pediatric thyroid disease: complication rates after thyroidectomy at the Children's Hospital of Philadelphia high-volume pediatric thyroid center. J Pediatr Surg 54(10):1969-1975. https://doi.org/10.1016/j. jpedsurg.2019.02.009
35. Sosa JA, Tuggle CT, Wang TS, Thomas DC, Boudourakis L, Rivkees S, Roman SA (2008) Clinical and economic outcomes of thyroid and parathyroid surgery in children. J Clin Endocrinol Metab 93(8):3058-3065. https://doi.org/10.1210/jc.2008-0660

36. Wang TS, Roman SA, Sosa JA (2009) Predictors of outcomes following pediatric thyroid and parathyroid surgery. Curr Opin Oncol 21(1):23-28. https://doi.org/10.1097/CCO. 0b013e32831897b6

37. Nordenstrom E, Bergenfelz A, Almquist M (2018) Permanent hypoparathyroidism after total thyroidectomy in children: results from a National Registry. World J Surg 42(9):2858-2863. https://doi. org/10.1007/s00268-018-4552-7

38. Machens A, Elwerr M, Schneider R, Lorenz K, Dralle H (2018) Disease impacts more than age on operative morbidity in children with Graves' disease after total thyroidectomy. Surgery 164(5):993997. https://doi.org/10.1016/j.surg.2018.07.021

39. Sherman J, Thompson GB, Lteif A, Schwenk WF 2nd, van Heerden J, Farley DR, Kumar S et al (2006) Surgical management of Graves disease in childhood and adolescence: an institutional experience. Surgery 140(6):1056-1061; discussion 1061-1052. https://doi.org/10.1016/j.surg.2006.07.040

40. Lang BH, Yih PC, Lo CY (2012) A review of risk factors and timing for postoperative hematoma after thyroidectomy: is outpatient thyroidectomy really safe? World J Surg 36(10):2497-2502. https://doi.org/10.1007/s00268-012-1682-1

41. Shandilya M, Kieran S, Walshe P, Timon C (2006) Cervical haematoma after thyroid surgery: management and prevention. Ir Med J 99(9):266-268

42. Barczyński M, Konturek A, Pragacz K, Papier A, Stopa M, Nowak W (2014) Intraoperative nerve monitoring can reduce prevalence of recurrent laryngeal nerve injury in thyroid reoperations: results of a retrospective cohort study. World J Surg 38(3):599-606. https:// doi.org/10.1007/s00268-013-2260-x

43. Tuggle CT, Roman SA, Wang TS, Boudourakis L, Thomas DC, Udelsman R, Sosa JA (2008) Pediatric endocrine surgery: who is operating on our children? Surgery 144(6):869-877; discussion 877. https://doi.org/10.1016/j.surg.2008.08.033

Publisher's note Springer Nature remains neutral with regard to jurisdictional claims in published maps and institutional affiliations. 